\title{
Gait dynamics in the wide spectrum of children with arthrogryposis: a descriptive study
}

\author{
Marie Eriksson ${ }^{1 *}$, Åsa Bartonek1, Eva Pontén ${ }^{1}$ and Elena M. Gutierrez-Farewik ${ }^{1,2}$
}

\begin{abstract}
Background: Arthrogryposis Multiplex Congenita (AMC) is a heterogeneous condition characterized by multiple joint contractures at birth. Greater movements in the trunk and pelvis during walking have been observed in children with AMC using orthoses compared to those wearing only shoes. This study investigated gait dynamics in children with AMC and identified compensatory mechanisms that accommodate walking.

Methods: Twenty-six children with AMC who walked with orthoses or shoes and a control group consisting of 37 typically-developing children were evaluated in 3D gait analysis. Children with AMC were divided into subgroups based on which joints needed to be stabilized in the sagittal plane; AMC1 used knee-ankle-foot orthoses (KAFOs) with locked knee joints, AMC2 used KAFOs with open knee joints or ankle-foot orthoses, and AMC3 used shoes.

Results: The Gait Deviation Index was lower in AMC groups than in the control group, with the lowest in AMC1. Excessive trunk movements in frontal and transverse planes were observed in AMC2 and especially in AMC1. Lower hip flexion moment was found in AMC1, while AMC2 and AMC3 showed similar hip flexion moments as the control group. Knee extension moments were similar between the groups. In the frontal plane there were only small differences between the groups in hip abduction moment. A joint work analysis indicated greater contribution from the hip muscles to overall positive work in $A M C$ groups, particularly in $A M C 1$, than in the control group.

Conclusion: All AMC groups showed less hip extension than the control group, but hip flexion moment was significantly lower only in $\mathrm{AMC1}$, which can be attributed to their gait strategy with bilateral locked KAFOs. AMC1, who had weak knee extensors, were helped by their locked KAFOs and therefore showed similar knee extension moment as the other groups. This finding, together with their gait patterns, demonstrates the children's high reliance on hip muscles and presumably trunk muscles to provide propulsion. Our study shows that with adequate orthotic support, children with AMC and even with severe weakness and contractures can achieve walking.
\end{abstract}

Keywords: Motion analysis, AMC, Trunk movements, Joint kinetics, Orthoses

\section{Background}

The primary attribute of Arthrogryposis Multiplex Congenita (AMC) is multiple joint contractures at birth [1]. The incidence is reported from 1 per 3000-5100 newborns $[1,2]$. According to Bevan et al. the most commonly reported affected areas in the lower extremities are foot and ankle joints followed by knee and hip joints [3]. Treatment of contractures in a child with AMC

\footnotetext{
* Correspondence: marie.eriksson@ki.se

'Department of Women's and Children's Health, Karolinska Institutet, Stockholm, Sweden

Full list of author information is available at the end of the article
}

commences soon after birth with stretching in combination with splints or serial casting that hold the joint in an optimal position [3], with goals to increase range of motion, preserve and enhance muscle strength [3], and position the joint well biomechanically. During childhood, contractures and deformities tend to recur, and surgical treatment is often necessary to maintain ambulation or improve lower limb function [4-6].

In children with $\mathrm{AMC}$, functional ambulation ability depends on factors such as severity of lower limb deformities and muscle weakness, primarily in hip and knee extensors $[5,7]$. As such, knee-ankle-foot orthoses 
(KAFOs) with locked knee joints or ankle-foot orthoses (AFOs) are often used to enable or improve walking function $[4,5,8,9]$. Use of KAFOs with open knee joints has also been described $[8,9]$. In children with AMC with plantarflexor weakness, use of a carbon fiber spring ankle joint has been considered to improve some gait parameters [10].

Lower activity level [11], functional exercise capacity [9], and higher oxygen cost and thereby less efficient gait, particularly in those walking with KAFOs with open knee joints or AFOs [9], have been reported. Children with AMC who use orthoses have been shown to walk with greater trunk and pelvis movements than those who do not use orthoses [8]. Reduced internal hip abduction moments have been reported in barefoot children walking with excessive lateral trunk movements, attributed to hip abductors weakness [12].

There are to date very few studies reporting gait dynamics (both kinematics and kinetics) in children with AMC. Objectives were therefore to describe gait dynamics in children with AMC in their highest possible level of functional ambulation.

\section{Methods}

Children with AMC born between 1993-2008 who were treated at the Department of Pediatric Orthopaedic Surgery of Karolinska University Hospital, Stockholm or Uppsala University Hospital, were invited to participate. Inclusion criteria were four limb or lower limb deformities or contractures, independent ambulation with or without orthoses, and age $5-18$ years. Of the 35 children eligible for inclusion, seven declined participation, one child who used a prosthesis was excluded, and one child was excluded due to lack of kinetic data; thus 26 children participated in the study with median [range] age 10.3 [5.0-17.8] years, weight 30.4 [16.5-98.0] $\mathrm{kg}$, and height 136.8 [103.0-173.0] cm. This study was approved by the Regional Ethical Review Board in Stockholm, Sweden. Informed consent was obtained, verbally from the children and written from the parents.

A control group consisting of 37 typically-developing (TD) children, age 9.7 [5.1-17.6] years, weight 34.1 [17.6-84.1] kg, and height 136.0 [111.0-185.5] cm, was used as reference group.

\section{Clinical examination and functional ambulation}

All participants underwent a physical examination by the same examiner ( $\mathrm{B})$, including assessment of passive range of motion [13] and manual muscle strength testing [14] in the lower extremities. Hip flexion, knee flexion, and plantarflexion contractures were defined as $>0^{\circ}$ from neutral position. Knee hyperextension was defined as $\geq 10^{\circ}$. No children had dislocated hips at the time of the study. Functional ambulation was assessed according to a five-level scale [15], with and without orthoses (Table 1). Nineteen of 26 children had some upper extremity involvement. No child used any walking aids.

\section{Orthopedic surgical history}

Orthopedic surgical history was retrieved from the medical records. Surgery in more than one joint at the same time was considered as multiple procedures.

\section{AMC subgroups}

The current orthotic programme at Karolinska University Hospital contains subgroups of children with walking ability, based on presence of muscle weakness and need for joint stabilization. The subgroups are children who require: 1) knee and ankle stabilization for knee extensor weakness grade $\leq 3,2$ ) ankle stabilization for plantarflexor and dorsiflexor weakness grade $\leq 3$, and 3 ) only foot stabilization.

Five children were designated subgroup 1 (AMC1) and used KAFOs with locked knee joints (KAFO-LK) which stabilize the knee and ankle in all planes. Ten children were designated subgroup 2 (AMC2); eight children used AFOs which stabilize the ankle in all planes and two used KAFOs with open knee joints (KAFO-O) with unrestricted knee flexion which further stabilize the knee in frontal and transverse planes. Six of the 15 children using orthoses had carbon fiber spring ankle joints, two in AMC1 and four in AMC2. Eleven children were designated subgroup 3 (AMC3) with only shoes, of which 2 children had additional FO (Table 1). To improve biomechanical alignment when required, heel height was adjusted in the orthoses and/or shoes based on each participant's contracture.

\section{Gait analysis}

All children underwent 3D gait analysis using an eightcamera system (Vicon ${ }^{\circ}$, Oxford, UK) and full-body 35marker set (Plug-In-Gait) at a self-selected comfortable pace along a 10-m walkway with two embedded force plates (Kistler ${ }^{\odot}$, Switzerland). Joint kinetic information was computed using inverse dynamics.

\section{Data analysis}

At least three gait cycles per side were collected for each subject. The Gait Deviation Index (GDI), which summarizes lower body kinematic parameters into a multivariate measure of overall gait deviations, was computed. A GDI of approximately 100 reflects normal kinematics and each 10-point reduction represents one standard deviation from normal [16]. GDI was calculated for left and right sides individually. Normal GDI was computed from the lab's database of 37 TD children.

Kinematic and kinetic parameters were obtained from each gait cycle and averaged for each side. Internal joint 
Table 1 Groups, orthoses, functional ambulation, joint contractures, muscle strength, and functional ambulation without orthoses

\begin{tabular}{|c|c|c|c|c|c|c|c|c|c|c|c|c|c|}
\hline \multirow[t]{4}{*}{ Subject } & \multirow[t]{4}{*}{ Group } & \multirow[t]{4}{*}{ Orthoses } & \multirow{4}{*}{$\begin{array}{l}\text { Functional } \\
\text { ambulation }\end{array}$} & \multicolumn{3}{|c|}{ Joint contractures $\left({ }^{\circ}\right)$} & \multicolumn{6}{|c|}{ Muscle strength (grade $0-5$ ) } & \multirow{4}{*}{$\begin{array}{l}\text { Functional } \\
\text { ambulation } \\
\text { without } \\
\text { orthoses }\end{array}$} \\
\hline & & & & \multirow{3}{*}{$\begin{array}{l}\text { Hip } \\
\text { Flexion } \\
\text { L/R }\end{array}$} & \multirow{3}{*}{$\begin{array}{l}\text { Knee } \\
\text { Flexion } \\
\text { L/R }\end{array}$} & \multirow{3}{*}{$\begin{array}{l}\text { Plantar } \\
\text { Flexion } \\
\text { L/R } \\
\end{array}$} & \multicolumn{3}{|l|}{ Hip } & \multirow{3}{*}{$\begin{array}{l}\text { Knee } \\
\text { Extension } \\
L / R \\
\end{array}$} & \multicolumn{2}{|l|}{ Ankle } & \\
\hline & & & & & & & Flexion & Extension & Abduktion & & Dorsiflexion & Plantarflexion & \\
\hline & & & & & & & $L / R$ & $L / R$ & $L / R$ & & $L / R$ & $L / R$ & \\
\hline 1 & AMC1 & KAFO-LK & III & $10 / 20$ & $30 / 30$ & $20 / 20$ & $4 / 4$ & $3 / 1$ & $3 / 3$ & $2 / 2$ & $0 / 0$ & $0 / 0$ & V \\
\hline 2 & & KAFO-LK & III & $5 / 5$ & 20/15 & -15 & $2 / 2$ & $3 / 3$ & $2 / 2$ & $2 / 2$ & $1 / 1$ & $1 / 1$ & V \\
\hline 3 & & KAFO-LK-C & III & & $20 /+15^{b}$ & $40 / 50$ & $3 / 3$ & $4 / 4$ & $4 / 4$ & $3 / 3$ & $0 / 0$ & $0 / 0$ & V \\
\hline 4 & & KAFO-LK & III & & $-/ 10$ & $20 / 20$ & $4 / 4$ & $4 / 4$ & $4 / 4$ & $3 / 3$ & $0 / 0$ & $0 / 0$ & V \\
\hline 5 & & KAFO-LK-C & III & & $30 / 30$ & $25 / 25$ & $3 / 3$ & $4 / 4$ & $4 / 4$ & $3 / 3$ & $1 / 1$ & $1 / 1$ & V \\
\hline 6 & AMC2 & KAFO-O-C & III & & $15 / 5$ & 10/- & $4 / 4$ & $4 / 4$ & $4 / 4$ & $4 / 3$ & $0 / 0$ & 0/0 & IV \\
\hline 7 & & AFO-H & $\|$ & -15 & $+15 /+10$ & $5 /-$ & $4 / 4$ & $4 / 4$ & $4 / 4$ & $5 / 5$ & $3 / 4$ & $4 / 4$ & $\|$ \\
\hline 8 & & AFO-FC & $\|$ & & $+10 /+10$ & & $4 / 4$ & $4 / 4$ & $4 / 4$ & $4 / 4$ & $4 / 4$ & $3 / 3$ & III \\
\hline 9 & & AFO-S & III & & $15 / 15$ & & $4 / 4$ & $4 / 4$ & $3 / 3$ & $4 / 4$ & $4 / 4$ & $2 / 2$ & IV \\
\hline 10 & & KAFO-O-C & $\|$ & 5/- & $10 / 5$ & $15 /-$ & $4 / 4$ & $4 / 4$ & $4 / 4$ & $4 / 4$ & $1 / 1$ & $2 / 2$ & III \\
\hline 11 & & AFO-H & $\|$ & $5 /-$ & $+20 /+20$ & & $4 / 4$ & $4 / 4$ & $4 / 4$ & $4 / 4$ & $4 / 4$ & $2 / 2$ & III \\
\hline 12 & & AFO- $C^{a}$ & $\|$ & & $-/ 5$ & $-/ 10$ & $5 / 5$ & $5 / 4$ & $5 / 4$ & $5 / 4$ & $4 / 3$ & $5 / 3$ & $\|$ \\
\hline 13 & & AFO-S ${ }^{a}$ & $\|$ & & $-/ 5$ & & $4 / 4$ & $4 / 4$ & $4 / 4$ & $5 / 5$ & $5 / 3$ & $5 / 3$ & $\|$ \\
\hline 14 & & AFO-C & $\|$ & & & & $5 / 5$ & $4 / 4$ & $4 / 4$ & $5 / 5$ & $4 / 4$ & $3 / 3$ & $\|$ \\
\hline 15 & & AFO-FC & $\|$ & & $-/+10$ & 20/- & $5 / 5$ & $4 / 4$ & $4 / 4$ & $4 / 4$ & $2 / 2$ & $2 / 2$ & $\|$ \\
\hline 16 & AMC3 & Shoes & 1 & $10 / 10$ & & & $5 / 5$ & $4 / 4$ & $4 / 4$ & $4 / 4$ & $4 / 4$ & $4 / 4$ & 1 \\
\hline 17 & & Shoes & 1 & & $5 / 10$ & & $4 / 4$ & $4 / 4$ & $4 / 4$ & $4 / 4$ & $4 / 3$ & $3 / 3$ & 1 \\
\hline 18 & & Shoes + FO & 1 & & $5 /-$ & 10/- & $5 / 5$ & $4 / 4$ & $4 / 4$ & $4 / 4$ & $4 / 4$ & $4 / 4$ & 1 \\
\hline 19 & & Shoes & I & $10 / 10$ & $+10 /+20$ & & $5 / 5$ & $4 / 4$ & $5 / 5$ & $5 / 5$ & $5 / 5$ & $5 / 5$ & 1 \\
\hline 20 & & Shoes & I & & $+10 /+10$ & & $5 / 5$ & $5 / 5$ & $4 / 4$ & $5 / 5$ & $4 / 4$ & $5 / 5$ & 1 \\
\hline 21 & & Shoes & 1 & & $+15 /+15$ & & $5 / 5$ & $4 / 4$ & $4 / 4$ & $4 / 4$ & $4 / 4$ & $4 / 4$ & 1 \\
\hline 22 & & Shoes & I & & -15 & & $5 / 5$ & $5 / 5$ & $5 / 5$ & $5 / 5$ & $4 / 4$ & $5 / 5$ & I \\
\hline 23 & & Shoes + FO & 1 & & -15 & & $4 / 4$ & $4 / 4$ & $4 / 4$ & $4 / 4$ & $3 / 4$ & $4 / 4$ & I \\
\hline 24 & & Shoes & 1 & $-/ 10$ & $5 / 5$ & & $5 / 5$ & $5 / 5$ & $5 / 5$ & $4 / 4$ & $4 / 4$ & $4 / 4$ & 1 \\
\hline 25 & & Shoes & I & & & & $5 / 5$ & $5 / 5$ & $5 / 5$ & $4 / 4$ & $4 / 4$ & $4 / 4$ & 1 \\
\hline 26 & & Shoes & I & $-/ 10$ & $-/+10$ & 5/- & $4 / 4$ & $5 / 5$ & $5 / 5$ & $4 / 4$ & $4 / 4$ & $5 / 5$ & 1 \\
\hline
\end{tabular}

KAFO knee-ankle-foot orthosis, $L K$ locked knee joint, $C$ carbon fiber ankle joint, $O$ open knee joint with extension stop, $A F O$ ankle-foot orthosis, $H$ hinged with restricted range of motion, $F C$ flexible carbon fiber, $S$ solid, $F O$ foot orthosis, I community ambulators with no need for a wheelchair, II community ambulators who require a wheelchair for long distances outdoors only, III household ambulators and wheelchairs users outdoors and long distances indoors, $I V$ household ambulators and wheelchair users both outdoors and indoors, $V$ non-functional ambulation and wheelchair use for mobility, $L$ left, $R$ right

+ indicates hyperextensio

a unilaterally

${ }^{\mathrm{b}}$ hyperextension is prevented by orthosis 
moments were normalized to body weight. Joint work was calculated as the time integral of joint power. Positive and negative joint work in the lower limbs was computed, and contributions from the hip, knee and ankle were computed as percentages of total positive work in the lower extremities (hip + knee + ankle work).

Step length, stride length, walking speed, and cadence were non-dimensionalized [17].

\section{Statistical analysis}

The Wilcoxon signed-rank test was used to evaluate differences in GDI between sides. The Kruskal-Wallis test was used to evaluate differences between AMC1, AMC2, $\mathrm{AMC} 3$, and the control group, followed-up by a post hoc Mann-Whitney $U$ test. Chi-Square test was used to evaluate differences in numbers of performed orthopedic surgery in lower limb and spine between AMC groups. Statistical analyses were carried out using commerciallyavailable software (SPSS 21.0). Significance level was set at $p<0.05$.

\section{Results}

There was no difference in GDI between sides ( $p=0.648$ ) in the entire AMC group. The side with the lowest GDI in each participant was used for further data analysis. For the control group, the side for further analysis was chosen randomly. Results for GDI, kinematics, internal joint moments and joint work are reported as median and interquartile range, and the results for each joint's contribution to total positive work are reported as means.

\section{Description of gait}

All subjects in AMC1 displayed large deviations in trunk and pelvic movements in all planes. They had a constant knee flexion angle as a consequence of the locked orthotic knee joints (Fig. 1). AMC1 displayed prolonged hip extension moment with a late crossover and a short period of low hip flexion moment in late stance. Hip abduction/adduction moment varied among the participants (Fig. 2). Only subject 2 showed a net hip adduction moment instead of abduction moment - this child had hip abductor weakness and walked with approximately $15^{\circ}$ trunk lateral sway and nearly $20^{\circ}$ contralateral pelvic elevation (Figs. 1 and 2, black dashed line). All other had some hip abduction moment during stance (Fig. 2).

There was no characteristic gait pattern in AMC2; we observed a particularly large variation among the participants in hip frontal kinematics, pelvis sagittal kinematics, and in trunk and pelvic rotation (Fig. 3). Hip joint moments and knee joints moments in frontal and sagittal planes also varied within the group (Fig. 4). One participant, subject 6, showed large deviations in lateral trunk sway and in trunk and pelvic rotation. This child had a late crossover from hip extension to hip flexion moment - with an anterior pelvic tilt of approximately $35^{\circ}$, he did not take advantage of his available hip extension, and had a large range of trunk tilt movement (Figs. 3 and 4, dark blue dashed line).

The AMC3 group displayed the relatively fewest gait deviations. Trunk and pelvis kinematics in all planes varied among the participants, but the range of motion during the entire gait cycle in each subject was relatively small. Six children showed less hip extension in late stance, of which 3 had hip flexion contractures of $10^{\circ}$ and 3 did not utilize their full hip extension (Fig. 5). One of the children, subject 26, who showed less hip extension during stance due to hip flexion contracture of $10^{\circ}$, had anterior pelvic tilt of nearly $40^{\circ}$. During swing, her knee flexion was limited by her available flexion range of motion of $20^{\circ}$. At initial contact, her knee joint was slightly hyperextended and the knee flexion/extension moment was altered with absence of the first peak knee extension moment (Figs. 5 and 6, pink dashed line). Variation was found in the sagittal plane moments among the subjects, particularly in the knee joint (Fig. 6).

\section{Comparison of groups}

The GDI was lower in all AMC groups compared to the control group, with the lowest in AMC1. Both AMC2 and AMC1 showed greater trunk lateral sway and rotation than AMC3 and the control group. AMC1 had approximately two times greater pelvic rotation than the other groups. All AMC groups showed greater anterior pelvic tilt and less hip extension than the control group. AMC3 showed greater knee flexion during midstance and had greater dorsiflexion during stance than the control group. All AMC groups had less plantarflexion than the control group (Table 2).

Maximum hip flexion moment was lower in AMC1 than in the other groups. Maximum knee extension moment did not differ between the groups but maximum knee flexion moment in midstance was lowest in AMC3. AMC2 showed a lower average knee valgus moment than the other groups, though not significantly. Plantarflexion moment was lower in AMC1 and AMC2 than in AMC3 and the control group (Table 2).

AMC3 and the control group did most of their positive work at the ankle and the most of their negative work at the knee. AMC1 did the greatest positive and greatest negative work in the hip joint. AMC2 did the most of their positive work at the hip joint and most of their negative work at the knee joint (Table 2).

The hip's contribution to total positive work differed significantly between the groups, wherein all AMC groups had greater than the control group, with the greatest in AMC1 followed by AMC2 and then AMC3. The knee's contribution to total positive work differed significantly between the groups, with the lowest in AMC1. The ankle's 

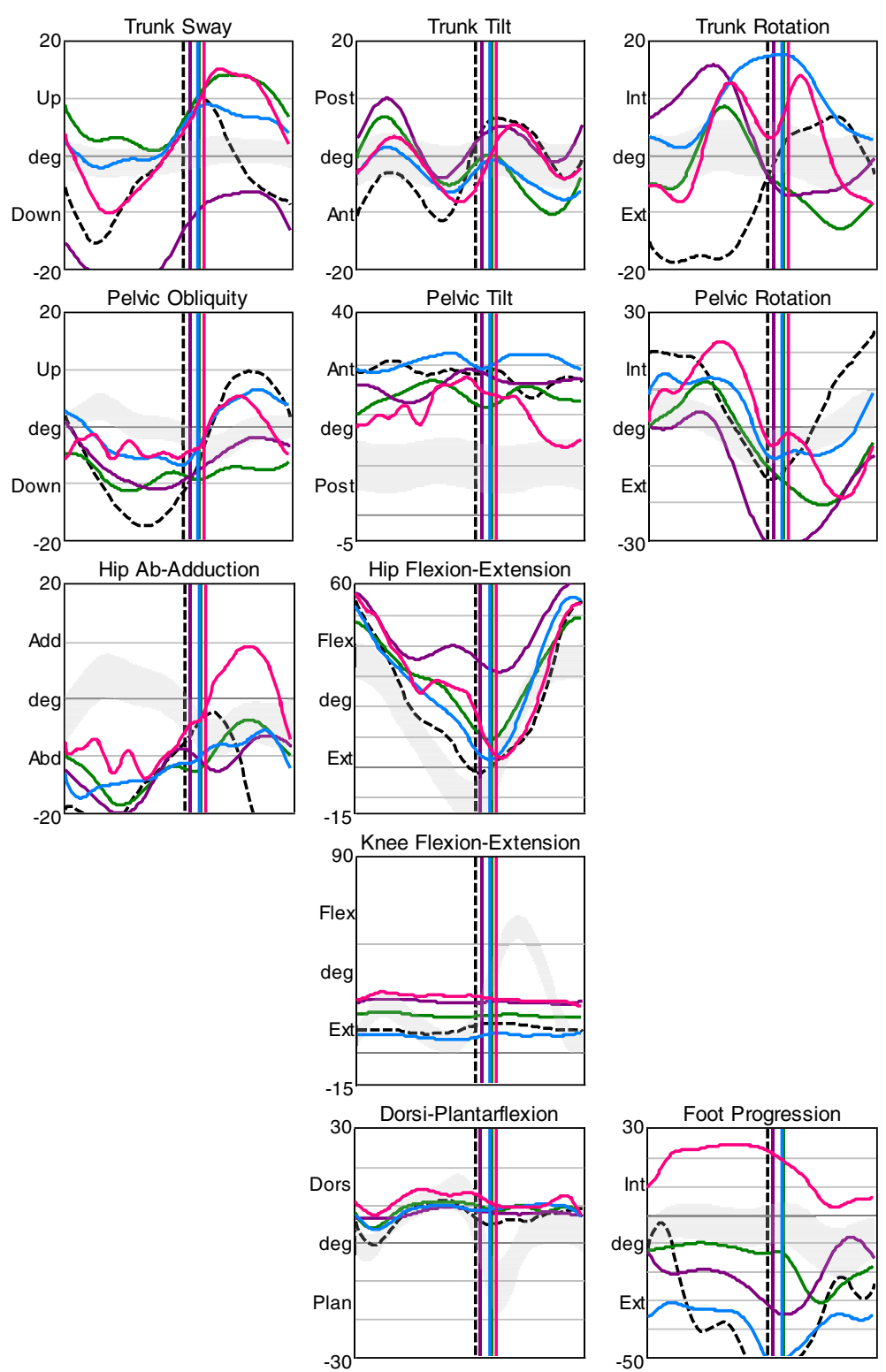

- Subject 1, ----- Subject 2,

Subject 3,

Subject 4,

Subject 5

Fig. 1 Kinematics in AMC1. Movements in the trunk and pelvis segments, and in the hip, knee, and ankle joints in all planes for AMC1. The shaded field represents the mean \pm 1 SD of the gait laboratory control group, and each line represents one individual in this group

contribution to total positive work differed significantly between the groups, wherein AMC1 had lower than any other groups (Fig. 7).

The cadence was lower in AMC1 than in all other groups. The walking velocity was lower in AMC1 than in AMC2 and the control group. The step length and stride length did not differ significantly between the groups (Table 2).

\section{Performed orthopedic surgery}

Orthopedic surgical corrections of deformities in the lower limbs had been performed on 23 children. Two children had undergone spine surgery for correction of scoliosis. There was no significant difference between groups in number of performed orthopedic procedures $(p=0.185)$. Performed surgery in lower limb and spine for each subject are shown in Table 3.

\section{Discussion}

AMC is a group of heterogeneous disorders characterized by multiple joint contractures [18]; in our study, we have illustrated the diversity of gait in children with AMC, but have not been able to identify overall characteristic gait patterns in this patient population. Variations due to their 

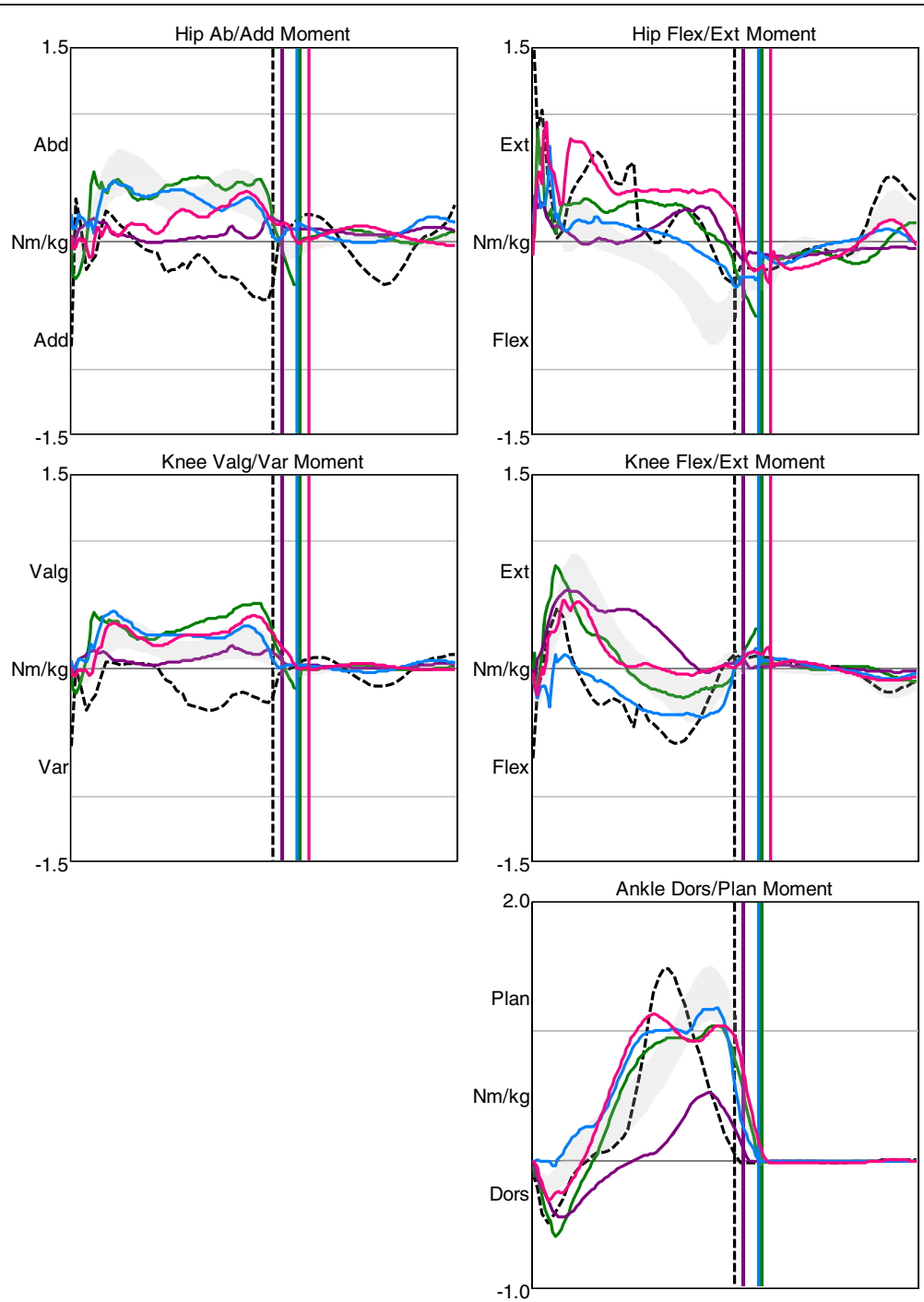

Subject 1, ----- Subject 2 ,

Subject 3,

Subject 4 ,

Subject 5

Fig. 2 Joint moments in AMC1. Moments in the hip, knee, and ankle joints in the frontal and sagittal planes for AMC1. The shaded field represents the mean \pm 1 SD of the gait laboratory control group, and each line represents one individual in this group

individual requirements are common. We have instead tried to classify the participants into subgroups depending on need for joint stabilization, and to describe gait dynamics in their highest possible level of ambulation. Wheelchair use was reported in 12/26 children as a complement to walking, including the entire AMC1 group, which relates to previous findings of higher energy effort during walking in children with AMC [9]. Hip flexion contracture of less than $20^{\circ}-30^{\circ}$ and active hip motion have been reported as important factors for independent or community ambulation $[5,7]$. None of the children in our study group had hip flexion contractures greater than $20^{\circ}$, and all children had hip extensor strength of grade 4-5 except two in AMC1. In a group of children walking without orthoses, excessive trunk lean and pelvic elevation have been proposed as compensation for limited hip flexion movements and strength [19]. In our study group hip flexion weakness was found in 6/10 limbs in AMC1. Correlation between excessive ipsilateral trunk sway and reduced internal hip abduction moment has been reported in children with AMC walking barefoot [12] and was attributed as a compensatory solution for weak hip abductors [12], as previously been reported in children with myelomeningocele [20]. To improve quality of gait function and achieve a more efficient gait, the importance of hip joint stability has been advocated [4]. None of the children in our study group had dislocated hips at the time of gait analysis, and hip surgery had been performed in seven children.

In our study group, the foot and ankle joints were most frequently involved, which is in accordance with 

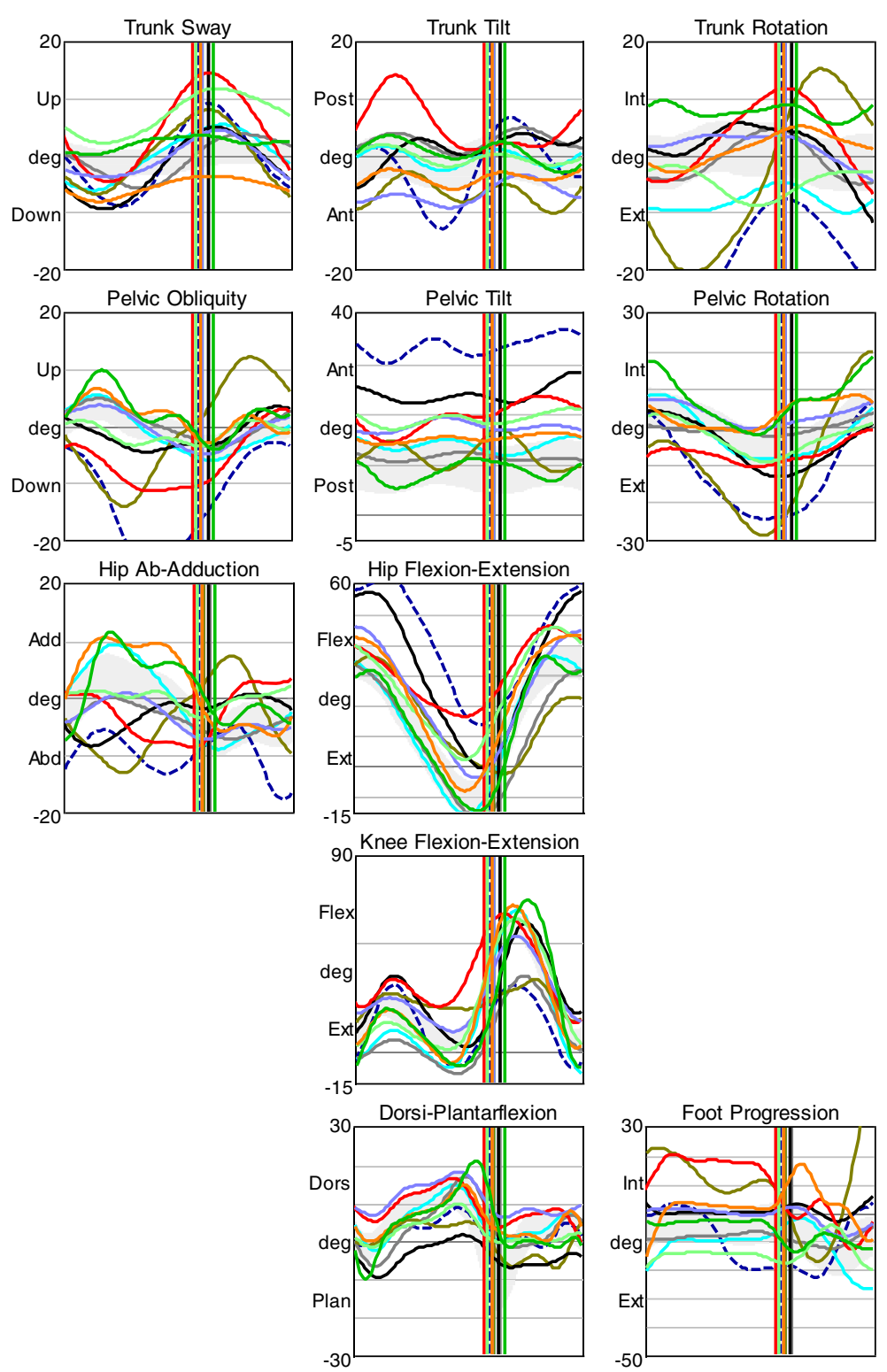

-----. Subject 6,

Subject 8 ,

Subject 9 , - Subject 10 ,

Subject 11, $\longrightarrow$ Subject 12 ,

Subject 13,

Subject 14,

Subject 15

Fig. 3 Kinematics in AMC2. Movements in the trunk and pelvis segments, and in the hip, knee, and ankle joints in all planes for AMC2. The shaded field represents the mean \pm 1 SD of the gait laboratory control group, and each line represents one individual in this group

Bevan et al. [3]. Different types of orthotic ankle joints were used to compensate for plantarflexor weakness and stabilize the ankle, but also according to each individual's acceptance, resulting in the observed spectrum of dorsi/ plantarflexion moments. Use of a carbon fiber spring ankle joint has been shown to increase plantarflexion moment in children with plantarflexor weakness [10]. Six children, distributed into AMC1 and AMC2 used orthoses with carbon fiber spring ankle joints.
A dominating attribute in AMC1 is knee extensor weakness; KAFOs with locked knee joints were therefore used to stabilize the knees. We attribute this group's excessive frontal and transverse trunk and pelvic movements as compensatory solutions for locked orthotic knee joints to advance the leg and clear the foot during swing. This gait pattern reduces the hip abduction moments. Hip flexion moment was low, which corresponds to their lack of hip extension during late stance 

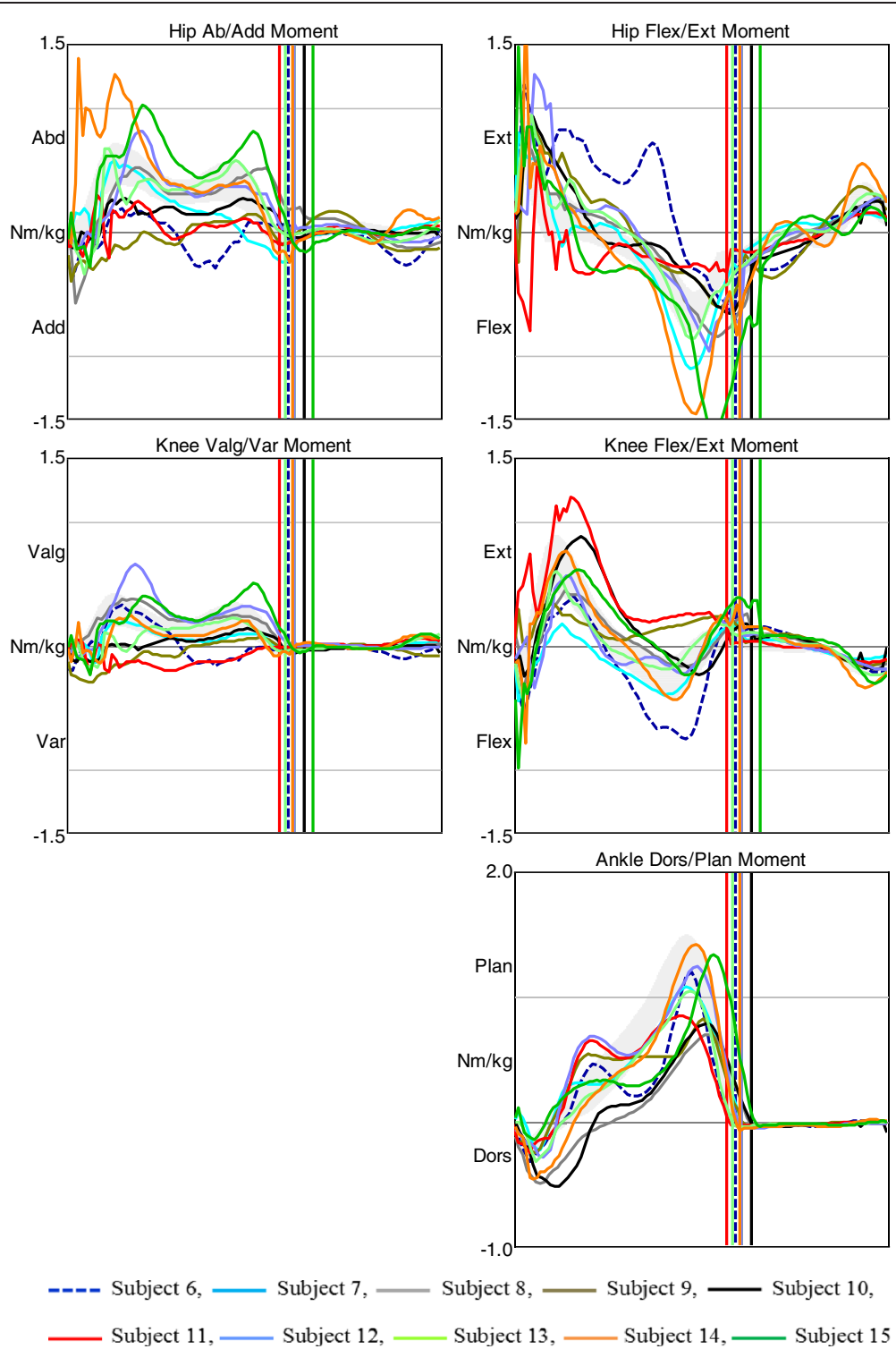

Fig. 4 Joint moments in AMC2. Moments in the hip, knee, and ankle joints in the frontal and sagittal planes for AMC2. The shaded field represents the mean \pm 1 SD of the gait laboratory control group, and each line represents one individual in this group

in combination with an exaggerated pelvic tilt. Two children in this group had hip flexion contractures and three children did not utilize their full hip extension, which might be a gait strategy when walking with bilateral locked KAFOs. Use of walkers to maintain balance has been described in children walking with locked KAFOs bilaterally [21]. All such children in the present study, however, preferred to walk without a walking aid. This also highlights the importance that orthoses/shoes should be tailored to compensate for each individual's contracture. During stance, the children's knees were restricted in a position corresponding to their knee flexion contractures of $10^{\circ}-30^{\circ}$. Their knee extension/flexion moments are therefore entirely due to orthoses.
The main attribute in AMC2 is plantarflexor weakness and therefore KAFOs with open knee joints or AFOs were used to stabilize the ankles. Knee varus instead of valgus moment was seen in two children using AFOs, of which one had hip abductor weakness and thereby also displayed stance hip adduction moment. The treatment concept of KAFOs with open knee joints is to stabilize the knee in frontal and transversal planes while not restricting knee flexion. Both children had used KAFO$\mathrm{O}$ previously but in recent years preferred AFOs. Hip flexion moment was similar to the control group but three children with less hip extension in late stance in combination with exaggerated pelvic tilt showed lower hip flexion moment. The similar knee extension/flexion 

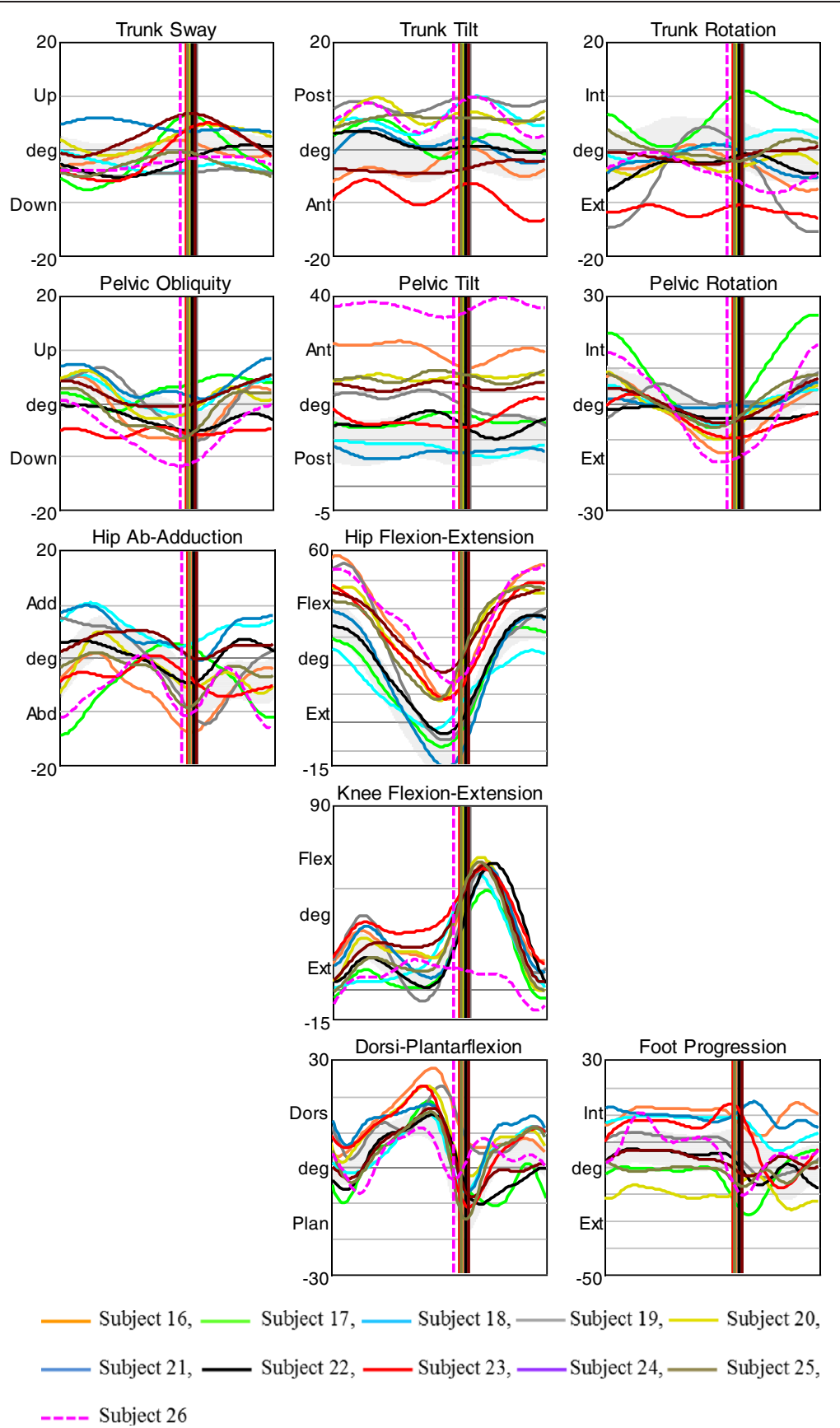

Fig. 5 Kinematics in AMC3. Movements in the trunk and pelvis segments, and in the hip, knee, and ankle joints in all planes for AMC3. The shaded field represents the mean \pm 1 SD of the gait laboratory control group, and each line represents one individual in this group

moment to the control group is likely due to orthoses stabilizing the ankle joint in the sagittal plane and knee flexion contractures less than $15^{\circ}$.

In AMC3, hip flexion moment was similar to that of the control group despite less hip extension during late stance and greater pelvic tilt. AMC3 had considerably lower knee flexion moment during midstance than other groups, corresponding to their greater passive dorsiflexion and corresponding lack of full knee extension. They had similar ankle moments as the control group, as they walked with only shoes and included only one child with some plantarflexor weakness.

In normal gait propulsion, approximately half of the positive work in the lower limbs is provided at the ankles 

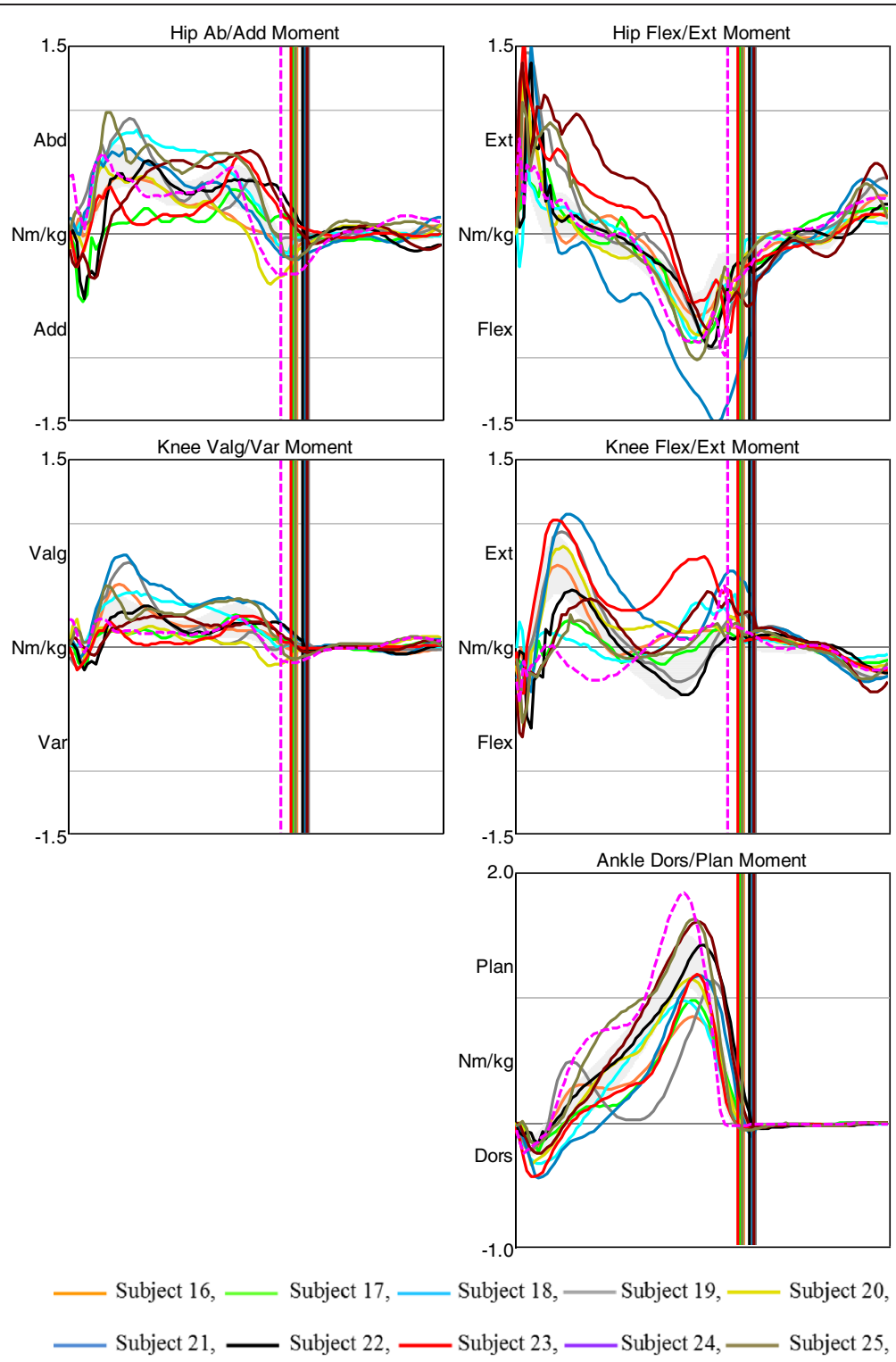

---- Subject 26

Fig. 6 Joint moments in AMC3. Moments in the hip, knee, and ankle joints in the frontal and sagittal planes for AMC3. The shaded field represents the mean \pm 1 SD of the gait laboratory control group, and each line represents one individual in this group

$[20,22]$. In the present study, all AMC groups displayed a proximal work shift, wherein the hip contributed more than the ankle to overall positive work. This was more pronounced in those walking with orthoses and particularly locked orthotic knee joints. The work analysis demonstrates that the children rely heavily on their hip muscles, and based on their trunk movements, presumably their core muscles to provide propulsion. AMC3 furthermore, had somewhat higher total positive work than TD children, which can be attributed to higher hip moments and higher total negative work in AMC3 but a similar walking speed to TD children.
The heterogeneity among the participants regarding joint contractures, muscle weakness and different types of orthoses used in this study might seem a limitation, but as it reflects the complexity of the condition, it was unavoidable. It could be also considered a study limitation that children with AMC were tested in orthoses or shoes rather than barefoot, but this choice was made deliberately; we have collected gait data on those who could walk barefoot, but the ambulation level was often lower or nonexistent. Children in AMC1 had no walking ability without orthoses and five of the children in AMC2 had a lower ambulation level without orthoses. 
Table 2 Gait Deviation Index, kinematics, joint kinetics, and time and distance parameters in groups

\begin{tabular}{|c|c|c|c|c|c|}
\hline & $\begin{array}{l}\text { AMC } 1 \\
(n=5)\end{array}$ & $\begin{array}{l}\text { AMC } 2 \\
(n=10)\end{array}$ & $\begin{array}{l}\text { AMC } 3 \\
(n=11)\end{array}$ & $\begin{array}{l}\text { Control group } \\
(n=37)\end{array}$ & $\begin{array}{l}P \text {-value } \\
\text { Kruskal- } \\
\text { Wallis }\end{array}$ \\
\hline Gait Deviation Index & $51.0[48.4,59.5] \mathrm{A} 2, \mathrm{~A} 3, \mathrm{C}$ & $76.7[62.0,83.1] \mathrm{A} 1, \mathrm{C}$ & $77.7[70.1,86.5] \mathrm{A} 1, \mathrm{C}$ & $98.5[95.1,106.0] \mathrm{A} 1, \mathrm{~A} 2, \mathrm{~A} 3$ & $<0.001$ \\
\hline \multicolumn{6}{|l|}{ Kinematics $\left({ }^{\circ}\right)$} \\
\hline \multicolumn{6}{|l|}{ Trunk } \\
\hline Tilt ant (average) ${ }^{\text {a) }}$ & $1.6[-1.9,2.4]$ & $0.4[-1.7,3.5]$ & $-1.4[-5.7,1.3]$ & $-0.8[-4.9,1.9]$ & 0.372 \\
\hline Lateral sway (range) & $16.4[13.4,26.0] \mathrm{A} 3, \mathrm{C}$ & $10.6[6.6,16.9] \mathrm{A} 3, \mathrm{C}$ & $4.8[3.7,7.5] \mathrm{A} 1, \mathrm{~A} 2$ & $4.3[3.3,5.3] \mathrm{A} 1, \mathrm{~A} 2$ & $<0.001$ \\
\hline Rotation (range) & $20.6[17.7,27.9] \mathrm{A} 3, \mathrm{C}$ & $13.9[8.5,22.5] \mathrm{A} 3, \mathrm{C}$ & $6.3[5.2,10.8] \mathrm{A} 1, \mathrm{~A} 2$ & $6.8[5.2,8.2] \mathrm{A} 1, \mathrm{~A} 2$ & $<0.001$ \\
\hline \multicolumn{6}{|l|}{ Pelvis } \\
\hline Tilt ant (average) & $25.0[21.8,28.9] \mathrm{A} 2, \mathrm{C}$ & $15.8[11.9,21.8] \mathrm{A} 1, \mathrm{C}$ & $18.5[14.0,23.3] \mathrm{C}$ & $10.0[7.0,14.3] \mathrm{A} 1, \mathrm{~A} 2, \mathrm{~A} 3$ & $<0.001$ \\
\hline Elevation (range) & $14.2[9.5,22.5] \mathrm{C}$ & $11.5[7.9,17.1] \mathrm{A} 3$ & $7.6[6.6,9.0] \mathrm{A} 2$ & $10.0[7.0,11.8] \mathrm{A} 1$ & 0.030 \\
\hline Rotation (range) & $31.9[24.1,39.3] \mathrm{A} 2, \mathrm{~A} 3, \mathrm{C}$ & $17.4[10.0,23.4] \mathrm{A} 1$ & $15.5[13.9,18.6] \mathrm{A} 1$ & $15.1[8.8,19.6] \mathrm{A} 1$ & 0.008 \\
\hline \multicolumn{6}{|l|}{ Hip } \\
\hline Extension (max) & $-3.7[-20.9,0.4] C$ & $2.0[-4.5,14.7] \mathrm{C}$ & $-7.6[-9.5,7.1] \mathrm{C}$ & $12.5[6.9,16.7] \mathrm{A} 1, \mathrm{~A} 2, \mathrm{~A} 3$ & $<0.001$ \\
\hline Flexion (max in swing) & $55.0[49.5,59.2] \mathrm{A} 2, \mathrm{~A} 3, \mathrm{C}$ & $43.5[36.5,49.6] \mathrm{A} 1, \mathrm{C}$ & $47.1[36.9,49.8] \mathrm{A} 1, \mathrm{C}$ & $33.5[29.9,38.7] \mathrm{A} 1, \mathrm{~A} 2, \mathrm{~A} 3$ & $<0.001$ \\
\hline Abduction (max) & $17.8[16.3,26.2] A 2, A 3, C$ & $7.5[5.8,12.6] \mathrm{A} 1$ & $8.0[5.6,13.5] \mathrm{A} 1$ & $7.8[5.4,9.4] \mathrm{A} 1$ & 0.004 \\
\hline \multicolumn{6}{|l|}{ Knee } \\
\hline Flexion (initial contact) ${ }^{b}$ ) & $17.3[9.1,23.9] \mathrm{A} 3, \mathrm{C}$ & $2.8[-4.3,15.1]$ & $3.8[-1.7,12.1] \mathrm{A} 1$ & $4.1[2.2,6.9] \mathrm{A} 1$ & 0.038 \\
\hline Flexion (min in midstance) ${ }^{\text {b) }}$ & $15.9[6.3,24.0] \mathrm{C}$ & $-2.0[-8.2,14.1]$ & $6.8[1.1,17.6] \mathrm{C}$ & $1.0[-3.6,5.6] \mathrm{A} 1, \mathrm{~A} 3$ & 0.006 \\
\hline Flexion (max in swing) & $17.9[10.7,25.3] A 2, A 3, C$ & $59.8[41.2,64.7] \mathrm{A} 1$ & $61.4[58.6,62.1] \mathrm{A} 1$ & $58.3[54.7,62.6] \mathrm{A} 1$ & 0.004 \\
\hline \multicolumn{6}{|l|}{ Ankle } \\
\hline Dorsiflexion (max) & $11.3[9.7,12.8] \mathrm{A} 3$ & $13.9[8.1,19.1]$ & $19.0[15.7,23.0] \mathrm{A} 1, \mathrm{C}$ & $13.2[9.2,15.9] \mathrm{A} 3$ & 0.002 \\
\hline Plantarflexion $(\max )^{c)}$ & $-4.6[-6.7,-1.6] \mathrm{A} 2, \mathrm{~A} 3, \mathrm{C}$ & $2.0[-0.7,7.3] \mathrm{A} 1, \mathrm{C}$ & $4.3[-0.1,11.1] \mathrm{A} 1, \mathrm{C}$ & $16.6[12.7,20.2] \mathrm{A} 1, \mathrm{~A} 2, \mathrm{~A} 3$ & $<0.001$ \\
\hline $\begin{array}{l}\text { External foot progression } \\
\text { (average) }{ }^{d)}\end{array}$ & $25.2[-3.1,31.1]$ & $0.7[-4.8,8.6]$ & $0.8[-3.7,9.3]$ & $2.7[0.0,7.5]$ & 0.163 \\
\hline \multicolumn{6}{|l|}{ Joint Moments (Nm/kg) } \\
\hline \multicolumn{6}{|l|}{ Hip } \\
\hline Flexion (max) & $0.367[0.236,0.579] \mathrm{A} 2, \mathrm{~A} 3, \mathrm{C}$ & $0.899[0.684,1.204] \mathrm{A} 1$ & $0.954[0.702,1.009] \mathrm{A} 1$ & $0.930[0.780,1.160] \mathrm{A} 1$ & 0.006 \\
\hline Abduction (average stance) & $0.176[-0.054,0.282]$ & $0.224[0.056,0.372]$ & $0.257[0.203,0.325]$ & $0.301[0.264,0.393]$ & 0.058 \\
\hline \multicolumn{6}{|l|}{ Knee } \\
\hline Extension (max) & $0.550[0.351,0.682]$ & $0.529[0.395,0.795]$ & $0.543[0.471,0.816]$ & $0.565[0.453,0.713]$ & 0.955 \\
\hline Flexion (max in mid-stance) & $0.222[0.064,0.532]$ & $0.235[0.061,0.412]$ & $0.064[-0.023,0.226] \mathrm{C}$ & $0.300[0.175,0.408] \mathrm{A} 3$ & 0.035 \\
\hline Valgus (average stance) & $0.247[-0.043,0.262]$ & $0.071[0.020,0.205]$ & $0.143[0.106,0.184]$ & $0.163[0.108,0.213]$ & 0.196 \\
\hline \multicolumn{6}{|l|}{ Ankle } \\
\hline Dorsiflexion (max) & $0.437[0.129,0.494]$ & $0.298[0.218,0.447] \mathrm{C}$ & $0.259[0.180,0.328]$ & $0.200[0.180,0.252] \mathrm{A} 2$ & 0.031 \\
\hline Plantarflexion (max) & $1.127[0.794,1.250] \mathrm{C}$ & $1.112[0.782,1.275] \mathrm{C}$ & $1.260[1.033,1.558]$ & $1.320[1.195,1.440] \mathrm{A} 1, \mathrm{~A} 2$ & 0.015 \\
\hline \multicolumn{6}{|l|}{ Work (J/kg) } \\
\hline \multicolumn{6}{|l|}{ Hip } \\
\hline Positive work & $0.185[0.127,0.375]$ & $0.284[0.183,0.397] \mathrm{C}$ & $0.218[0.181,0.348] \mathrm{C}$ & $0.170[0.110,0.210] \mathrm{A} 2, \mathrm{~A} 3$ & 0.008 \\
\hline Negative work & $0.082[0.041,0.162]$ & $0.171[0.098,0.191]$ & $0.148[0.049,0.176]$ & $0.130[0.073,0.180]$ & 0.403 \\
\hline
\end{tabular}


Table 2 Gait Deviation Index, kinematics, joint kinetics, and time and distance parameters in groups (Continued)

\begin{tabular}{|c|c|c|}
\hline \multicolumn{3}{|l|}{ Knee } \\
\hline Positive work & $0.022[0.013,0.049] \mathrm{A} 2, \mathrm{~A} 3, \mathrm{C}$ & $0.103[0.04$ \\
\hline Negative work & $0.035[0.021,0.074] \mathrm{A} 2, \mathrm{~A} 3, \mathrm{C}$ & $0.283[0.21$ \\
\hline \multicolumn{3}{|l|}{ Ankle } \\
\hline Positive work & $0.044[0.023,0.058] \mathrm{A} 2, \mathrm{~A} 3, \mathrm{C}$ & $\begin{array}{l}0.114[0.085, \\
A 3, C\end{array}$ \\
\hline Negative work & $0.058[0.024,0.081] \mathrm{A} 2, \mathrm{~A} 3$ & $\begin{array}{l}0.108[0.075, \\
\text { A3 }\end{array}$ \\
\hline \multicolumn{3}{|l|}{ Time and distance } \\
\hline $\mathrm{N}$ step length & $0.72[0.64,0.91]$ & $0.86[0.77,0$. \\
\hline $\mathrm{N}$ stride length & $1.43[1.31,1.75]$ & $1.71[1.58,1$. \\
\hline $\mathrm{N}$ cadence & $0.41[0.35,0.49] \mathrm{A} 2, \mathrm{~A} 3, \mathrm{C}$ & $0.56[0.54,0$. \\
\hline $\mathrm{N}$ walking speed & $0.291[0.239,0.434]$ & $0.498[0.446$, \\
\hline \multicolumn{3}{|c|}{$\begin{array}{l}\text { Median [interquartile range] of Gait Deviation Index, trunk and pelvis kinematics, } \\
\text { length, stride length, cadence, and walking speed in AMC1, AMC2, AMC3 and in } \\
\text { significant difference from A1: AMC1, A2: AMC2, A3: AMC3 and C: the Control gr } \\
\text { a) }_{-}=\text {posterior, }^{\text {b) }}{ }_{-=} \text {extension, }{ }^{c)}-=\text { dorsiflexion, }{ }^{d)}{ }_{-}=\text {internal }\end{array}$} \\
\hline \multicolumn{3}{|c|}{$\begin{array}{l}\text { We therefore analyzed what we believe is their opti- } \\
\text { mal and typical gait. It may have been optimal if } \\
\text { children in the control group had also walked with } \\
\text { shoes, as some gait parameters change slightly with } \\
\text { shoes [23]. In the present study, however, the magni- } \\
\text { tude of gait parameters differences between AMC } \\
\text { and control group were quite large, and we therefore } \\
\text { believe there is little risk of over-interpreting small } \\
\text { differences accounting to shoe use. It should also be } \\
\text { noted that while we computed the GDI, we only } \\
\text { used it to select which side to analyze. Since GDI } \\
\text { does not incorporate upper body movements, it } \\
\text { probably underestimates the true deviation in this } \\
\text { population. }\end{array}$} \\
\hline
\end{tabular}

\section{Conclusion}

Children with AMC have potential to achieve functional ambulation despite a wide spectrum of muscle weakness and joint contractures, with orthotic solutions ranging from locked KAFOs to AFOs to shoes only. While all children with AMC had gait deviations, the highest deviations were observed in children requiring the most extensive orthotic support. Their kinetic patterns indicate how children with a high degree of joint deformity and muscle weakness are able to walk. The hip contributed more to positive joint work in all AMC groups, particularly in $A M C 1$, than in TD children. For optimal use of muscle strength, it is important to minimize hip

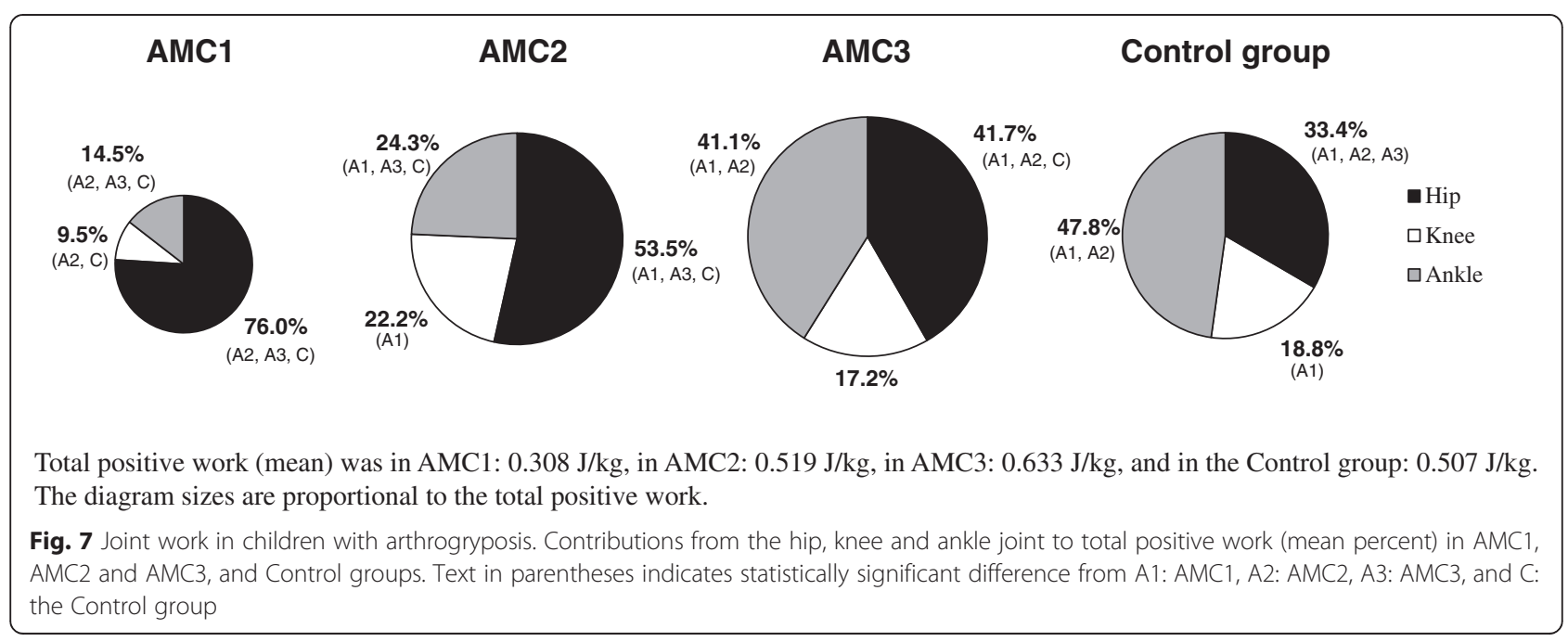


Table 3 Age (years) at the time of study participation, orthopaedic procedures, and side and age at performed surgery

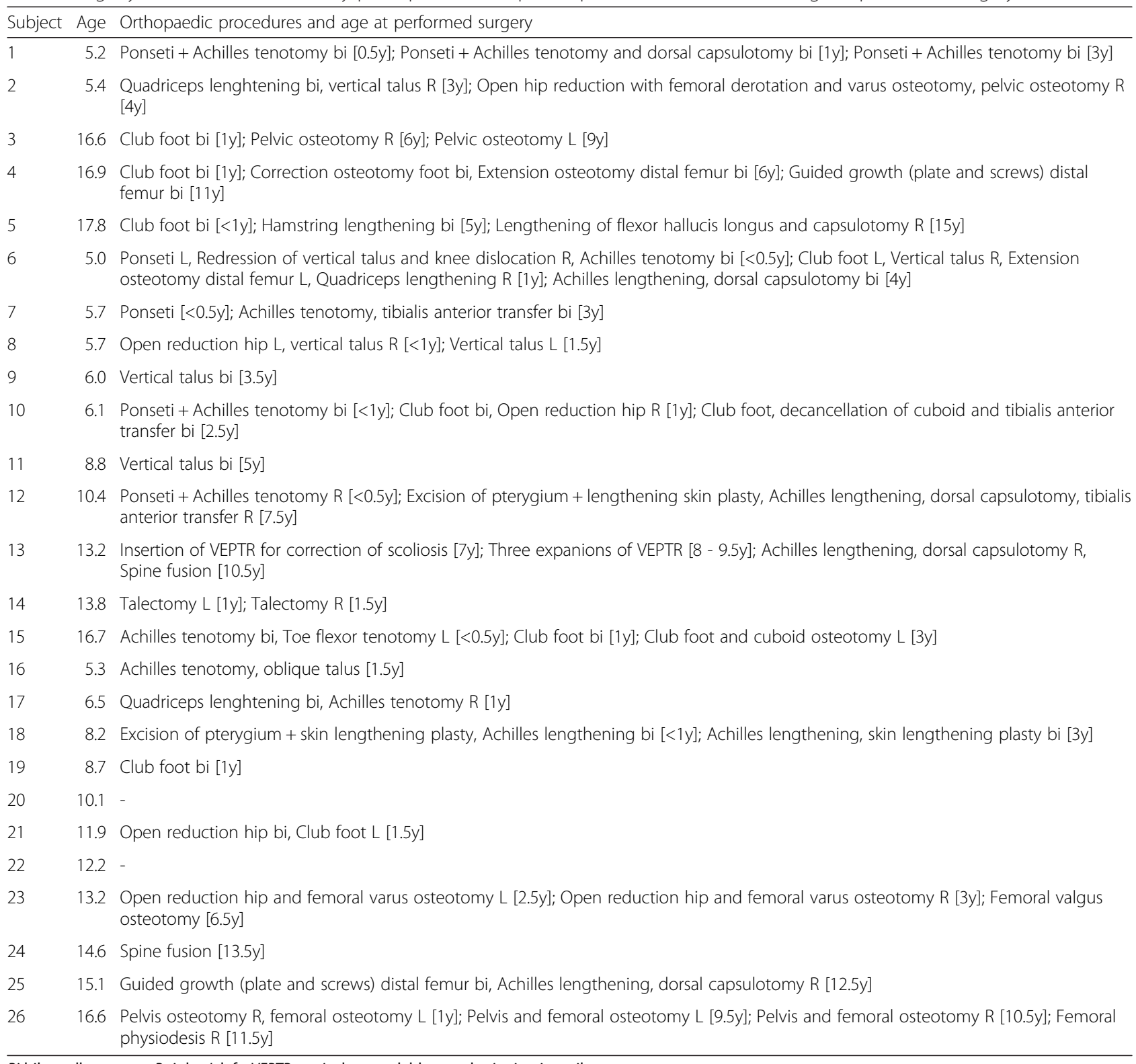

$B i$ bilaterally, $y$ years, $R$ right, $L$ left, VEPTR vertical expandable prosthetic titanium rib

flexion contractures, and preserve hip muscle strength in order to attain sufficient forward propulsion during walking. We believe that each child, based on his/her joint contractures, muscle weakness, and need for external stabilization, has developed an optimal and efficient gait.

\section{Competing interests}

The authors declare that they have no competing interests.

\section{Authors' contributions}

ME participated in the design of the study, carried out the data collection, processed the data, performed the statistical analyses, analyzed the data, and drafted the manuscript. ÅB conceived the study, carried out the data collection, analyzed the data, and actively improved and revised the manuscript. EP participated in the design of the study, analyzed the data, and actively improved and revised the manuscript. LGF conceived the study, processed the data, analyzed the data, and actively improved and revised the manuscript. Each of the authors has read and concur with the content in the final manuscript.

\section{Acknowledgements}

We would like to thank the children and their parents for participating in the study and physiotherapist Anna-Clara Esbjörnsson for collection of the control group. This study was supported by the Sunnerdahls Handikappfond and Promobilia Foundation.

\section{Author details}

'Department of Women's and Children's Health, Karolinska Institutet, Stockholm, Sweden. ${ }^{2}$ KTH Mechanics, Royal Institute of Technology, KTH BioMEx Center, Royal Institute of Technology, Stockholm, Sweden. 
Received: 3 September 2015 Accepted: 28 November 2015

\section{Published online: 09 December 2015}

\section{References}

1. Hall JG. Arthrogryposis multiplex congentia: etiology, genetics, classification, diagnostic approach, and general aspects. J Pediatr Orthop B. 1997;6(3):159-66.

2. Darin N, Kimber E, Kroksmark AK, Tulinius M. Multiple congenital contractures: birth prevalence, etiology, and outcome. J Pediatr. 2002;140(1): $61-7$.

3. Bevan WP, Hall JG, Bamshad M, Staheli LT, Jaffe KM, Song K. Arthrogryposis multiplex congenita (amyoplasia): an orthopaedic perspective. J Pediatr Orthop. 2007;27(5):594-600

4. Staheli LT. Lower extremity management. In: Staheli LT, Hall JG, Jaffe KM, Paholke DO, editors. Arthrogryposis: a text atlas. UK, Cambridge: Cambridge University Press; 1998. p. 55-73.

5. Fassier A, Wicart P, Dubousset J, Seringe R. Arthrogryposis multiplex congenita. Long-term follow-up from birth until skeletal maturity. J Child Orthop. 2009;3(5):383-90.

6. Ferguson J, Wainwright A. Arthrogryposis. Orthop Trauma. 2013;27(3):171-80.

7. Hoffer MM, Swank S, Eastman F, Clark D, Teitge R. Ambulation in severe arthrogryposis. J Pediatr Orthop. 1983;3(3):293-6.

8. Eriksson M, Gutierrez-Farewik EM, Brostrom E, Bartonek A. Gait in children with arthrogryposis multiplex congenita. J Child Orthop. 2010;4(1):21-31.

9. Eriksson M, Villard L, Bartonek A. Walking, orthoses and physical effort in a Swedish population with arthrogryposis. J Child Orthop. 2014;8(4):305-12.

10. Bartonek A, Eriksson M, Gutierrez-Farewik EM. Effects of carbon fibre spring orthoses on gait in ambulatory children with motor disorders and plantarflexor weakness. Dev Med Child Neurol. 2007:49(8):615-20.

11. Dillon ER, Bjornson KF, Jaffe KM, Hall JG, Song K. Ambulatory activity in youth with arthrogryposis: a cohort study. J Pediatr Orthop. 2009;29(2):214-7.

12. Stief F, Bohm H, Ebert C, Doderlein L, Meurer A. Effect of compensatory trunk movements on knee and hip joint loading during gait in children with different orthopedic pathologies. Gait Posture. 2014;39(3):859-64

13. American Academy of Orthopedic Surgeons. Joint Motion: method of measuring and recording. Edinburgh, London, Melbourne and New York: Churchill Livingstone; 1988.

14. Hislop HJ, Montgomery J. Daniel's and Worthingham's muscle testing: techniques of manual examination. 8th ed. St Louis: Saunders Elsevier; 2007.

15. Bartonek $\mathrm{A}$, Saraste $\mathrm{H}$. Factors influencing ambulation in myelomeningocele: a cross-sectional study. Dev Med Child Neurol. 2001;43(4):253-60.

16. Schwartz MH, Rozumalski A. The Gait Deviation Index: a new comprehensive index of pathology. Gait Posture. 2008;28(3):351-7.

17. Hof AL. Scaling gait data to body size. Gait Posture. 1996;4(3):222-3.

18. Hall JG. Arthrogryposis (multiple congenital contractures): Diagnostic approach to etiology, classification, genetics, and general principles. Eur J Med Genet. 2014;57(8):464-72.

19. Bohm H, Dussa CU, Multerer C, Doderlein L. Pathological trunk motion during walking in children with amyoplasia: is it caused by muscular weakness or joint contractures? Res Dev Disabil. 2013;34(11):4286-92.

20. Gutierrez EM, Bartonek A, Haglund-Akerlind Y, Saraste H. Kinetics of compensatory gait in persons with myelomeningocele. Gait Posture. 2005; 21(1):12-23.

21. Graubert GS, Chaplin DL, Jaffe KM. Physical and occupational therapy. In: Staheli LT, Hall JG, Jaffe KM, Paholke DO, editors. Arthrogryposis: a text atlas. UK, Cambridge: Cambridge University Press; 1998. p. 87-113.

22. Winter DA. Energy generation and absorption at the ankle and knee during fast, natural and slow cadences. Clin Orthop Related Res. 1983;175:147-54.

23. Oeffinger D, Brauch B, Cranfill S, Hisle C, Wynn C, Hicks R, et al. Comparison of gait with and without shoes in children. Gait Posture. 1999;9(2):95-100.

\section{Submit your next manuscript to BioMed Central and we will help you at every step:}

- We accept pre-submission inquiries

- Our selector tool helps you to find the most relevant journal

- We provide round the clock customer support

- Convenient online submission

- Thorough peer review

- Inclusion in PubMed and all major indexing services

- Maximum visibility for your research

Submit your manuscript at www.biomedcentral.com/submit 